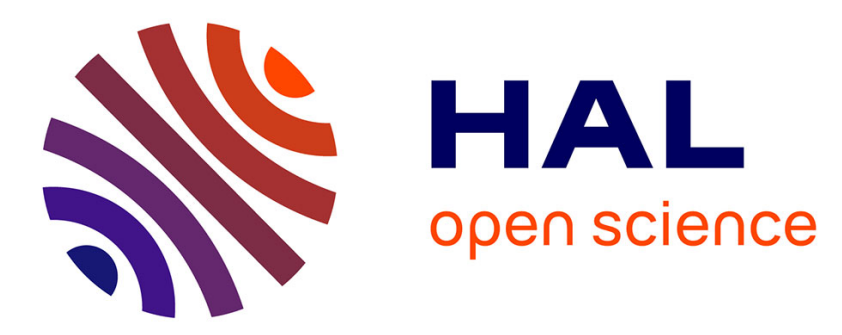

\title{
Extraction of phenolics from pomegranate residues: Selectivity induced by the methods
}

Christelle Harscoat-Schiavo, Besma Khoualdia, Raphaëlle Savoire, Samir Hobloss, Corinne Buré, Samia Ben Ali, Pascale Subra-Paternault

\section{- To cite this version:}

Christelle Harscoat-Schiavo, Besma Khoualdia, Raphälle Savoire, Samir Hobloss, Corinne Buré, et al. Extraction of phenolics from pomegranate residues: Selectivity induced by the methods. Journal of Supercritical Fluids, 2021, 176, pp.105300. 10.1016/j.supflu.2021.105300 . hal-03366229

\section{HAL Id: hal-03366229 \\ https://hal.science/hal-03366229}

Submitted on 5 Oct 2021

HAL is a multi-disciplinary open access archive for the deposit and dissemination of scientific research documents, whether they are published or not. The documents may come from teaching and research institutions in France or abroad, or from public or private research centers.
L'archive ouverte pluridisciplinaire HAL, est destinée au dépôt et à la diffusion de documents scientifiques de niveau recherche, publiés ou non, émanant des établissements d'enseignement et de recherche français ou étrangers, des laboratoires publics ou privés. 


\title{
Extraction of phenolics from pomegranate residues: selectivity induced by the methods
}

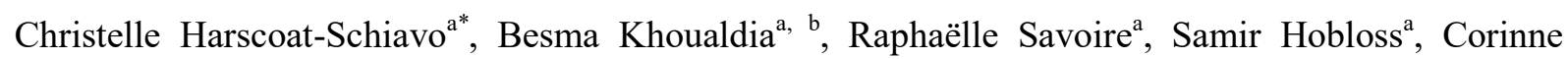
Buré, ${ }^{, a}$ Samia Ben Ali ${ }^{\mathrm{b}}$, Pascale Subra-Paternault ${ }^{\mathrm{a}}$

${ }^{a}$ Univ. Bordeaux, CNRS, Bordeaux-INP, CBMN, UMR 5248, 33600 Pessac, France.

${ }^{\mathrm{b}}$ Chemical-Process Engineering Department, National Engineering School of Gabes, University of Gabes, 6029 Gabes, Tunisia

\begin{abstract}
Pomegranate industrial residues are rich in highly valuable phenolics, especially the bioactive punicalagin (PU) and ellagic acid (EA). The effect of extraction conditions on the recovery of polyphenols was investigated with special insight at the selectivity for EA and PU, along with the monitoring of sugar extraction. Macerations in ethanol and/or water, extractions by $\mathrm{ScCO}_{2}$ :ethanol mixtures and pressurized ethanol were compared on the basis of yields, kinetics and extract composition. High extraction yields up to $61 \mathrm{~g} / 100 \mathrm{~g}_{\text {residue }}$ were obtained because of significant extraction of sugars even with $\mathrm{CO}_{2}$-based solvents. The TPC and sugar extraction yields were sensitive to the solvent polarity and pressure. Thirty-two phenolics were identified in most extracts whereas in $\mathrm{scCO}_{2}: \mathrm{EtOH}$ extracts purity of EA with respect to other phenolics was maximal, thus highlighting the selectivity of this technique. For the first time, extracts of high purity in EA and devoid of PU were produced in only one step.
\end{abstract}




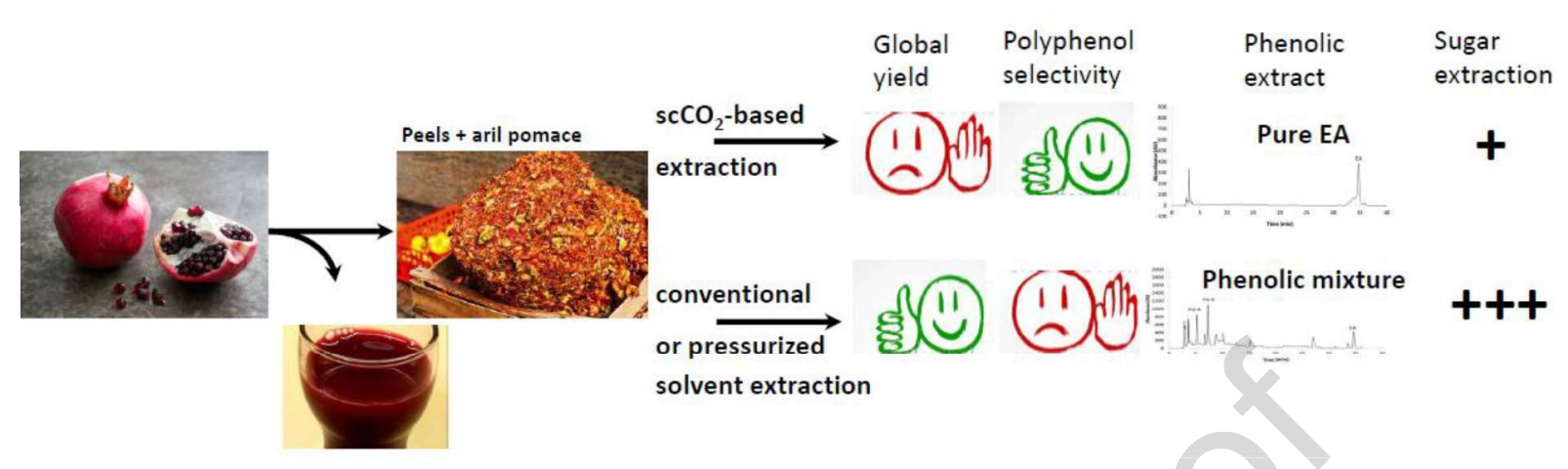

Keywords: pomegranate residue, selective extraction, ellagic acid, punicalagin, phenolic extracts, sugar content

\section{INTRODUCTION}

Pomegranate is a fruit widely grown in various countries from the Middle East, Far East, America, North Africa and South Europe [1]. Aside from its organoleptic and nutritional properties, pomegranate has antioxidant properties due to its high content in phenolics, anthocyanins and vitamin $\mathrm{C}$ [2]. In the last two decades, the demonstration of pomegranate healthy potential has led to a marked increase in its consumption especially as juices. In the few cases where juices are produced by squeezing arils only, peels and seeds come as separated residues that can be exploited as individual sources of phenolics and pomegranate oil, respectively. Actually, they are mostly produced by squeezing the whole fruits [3], an operation that releases huge amounts of residues that come as a mix of peels (73\%) and seeds (27\%) [3]. This residue is often disposed of without economic value though it contains the same bioactive compounds as the fruit edible parts. The recovery of these compounds of high potential for food, cosmetic or pharmaceutical applications [4] or the utilization of the residue as a source of functional fractions [5] would improve the eco-sustainability of the pomegranate processing industries [6].

The health potential of pomegranate fruits and extracts pertains to a wide range of biological properties generally attributed to the high content in polyphenolic components $[7,8]$ though no distinction is made between the various phenolics (anthocyanins, proanthocyanidins, hydrolysable tannins). However, the two major hydrolysable tannins of pomegranate, namely ellagic acid (EA) and punicalagin (PU), have shown distinct individual biological activities 
$[1,8,9]$. Among others, punicalagin has neuroprotective and chemotherapeutic effects $[10,11]$ and ameliorates obesity and obesity- induced inflammatory responses[12] whereas ellagic acid exhibits antioxidant, anti-inflammatory, anti-diabetes properties and offers protection of liver $[13,14]$. Thus, it would be worth implementing selective extractions in order to tune the extract composition upon the sought health outcome.

The extraction of antioxidant compounds from pomegranate by-products is extensively reported in the literature. However, most studies are carried out on peels $[4,8,15-19]$ and only two report extractions from the whole residue [20,21], with one in which peels and seeds were separated prior to their extraction [20]. Extractions are usually performed by maceration in aqueous and/or organic solvents [4,15], with occasionally a technological assistance by ultra sound, high pressure or enzymes [7,16,18,22-24], but very few studies report extraction by supercritical $\mathrm{CO}_{2}$ technology [16,20,24]. Regarding the extract characterization, studies mainly focus on the total phenolic content (TPC) that is an indicator of the antioxidant potential. On the other hand, pomegranate fruits are rich in carbohydrates like glucose and fructose [2]. Monitoring the extracts sugar content, a characteristic rarely addressed in literature, is therefore relevant.

The objectives and originality of the work were thus i) to compare various extraction techniques in terms of yields and extract composition, ii) the use of a whole pomegranate residue made of peels and seeds pomace, and iii) to address the extraction selectivity of ellagic acid and punicalagin. On the basis of conventional maceration extractions, the objective was to evaluate the possible added-value of adding $\mathrm{scCO}_{2}$ especially in terms of selectivity among extracted phenolic compounds. Various methods employing generally recognized as safe (GRAS) solvents were therefore implemented and compared, namely maceration in ethanol, in water and in their mixture, and extraction by $\mathrm{scCO}_{2}$ :ethanol and pressurized ethanol.

\section{MATERIALS AND METHODS}

\subsection{Material}

Fresh pomegranate fruits (Punica granatum L.) of El Gabsi variety were obtained from a local market in Gabes, Tunisia. Pomegranate fruits having approximately the same size $(\approx 8 \mathrm{~cm}$ diameter) were collected at full maturity and stored at $4^{\circ} \mathrm{C}$ until use (maximum storage time was 14 days). 
Ethanol for extraction (ethanol 96\%) and solvents for HPLC (HPLC grade methanol 99.8\%, formic acid 98\%) were purchased from Atlantic Labo (Bruges, France). Deionized water with a resistivity of $15 \mathrm{~m} \Omega . \mathrm{cm}$ (ELGA, Purelab ${ }^{\circledR}$ Option, UK) and $\mathrm{CO}_{2}(99.5 \%$ purity, Air Liquide, Floirac, France) were used. Folin reagent, sulfuric acid, anthrone, glucose, gallic acid, ellagic acid and punicalagin were from Sigma Aldrich (St Quentin Fallavier, France).

\subsection{Sample preparation}

Pomegranate fruits were peeled and the fresh arils were squeezed in a hand-squeezer to extract the juice. The squeezing operation left a pomace made of seeds and pulp. On a fresh weight basis, peels and pomace represented $62 \pm 7 \%$ and $38 \pm 9 \%$ of the fruit leftovers, respectively. Peels and pomace were separately freeze-dried and ground to powder in a coffee grinder then stored at $-18^{\circ} \mathrm{C}$ until use. Grinding was performed by batches of about $20 \mathrm{~g}$ of material, and each batch was carried out through four sequential $10 \mathrm{sec}$ grinding steps with manual mixing in between so as to avoid undesired heating of the ground material. For extractions, the peel and pomace powders were mixed in equivalent mass $(50: 50 \mathrm{w}: \mathrm{w})$ to reconstitute a pomegranate residue.

\subsection{Extraction methods}

The pomegranate residue was extracted by various methods, using either ethanol and/or water and/or $\mathrm{scCO}_{2}$ :ethanol mixture as solvents. All extractions were performed at $60^{\circ} \mathrm{C}$ since a mild heating at $52-67^{\circ} \mathrm{C}$ was reported to soften the plant tissue, weaken the cell wall integrity, hydrolyze phenol-protein and phenol-polysaccharide bonds and increase the phenolic compound solubility $[16,18]$. Regarding solvents, methanol and ethanol are both efficient to extract phenolics and antioxidants, but ethanol was preferred because of its food grade and GRAS status. 


\subsubsection{Maceration in ethanol, water, or mixture of ethanol:water (50:50 v:v)}

Ethanol, water and a mixture ethanol:water (50:50 v:v) were assessed for extractions by maceration. For each solvent, 3 successive extractions were carried out in order to exhaust the matrix. The pomegranate sample $(6.03 \mathrm{~g}+/-0.03 \mathrm{~g})$ and $60 \mathrm{~mL}$ solvent were mixed in a round-bottom flask equipped with a boil and condense system. The mixture was continuously stirred for two hours at $60{ }^{\circ} \mathrm{C}$. The phases were then separated by centrifugation at $3700 \mathrm{~g}$ for $10 \mathrm{~min}$ and the solid residue was further submitted to a second maceration while the supernatant was recovered. Thereafter, the solid residue was submitted to a third extraction. A total volume of $180 \mathrm{~mL}$ of solvent was therefore used for maceration. Extracts were kept in amber vials at $-18^{\circ} \mathrm{C}$ until analysis.

\subsubsection{Extraction by $\mathrm{ScCO}_{2}: \mathrm{EtOH}$ mixtures}

$\mathrm{CO}_{2}$-based extractions were performed using a home-made system previously described $[25,26]$. In this work, the extraction vessel of $10 \mathrm{~cm}^{3}(13 \mathrm{~mm}$ i.d. x $75 \mathrm{~mm} \mathrm{~L}$, TOP Industrie, Vaux le Penil, France) was filled with alternate layers of pomegranate sample and glass beads of $2 \mathrm{~mm}$ to avoid caking. About $4 \mathrm{~g}$ of pomegranate residue were loaded $(4.12+/-0.08 \mathrm{~g})$. The extractor was purged with a gentle flow of $\mathrm{CO}_{2}$ to remove air before being heated to the desired temperature of $60^{\circ} \mathrm{C}$ by an electric heating tape. $\mathrm{CO}_{2}$ was then introduced to pressurize the installation at the desired pressure of $25 \mathrm{MPa}$ and the system was stabilized at this pressure with neat $\mathrm{CO}_{2}$ flowing at $2.40+/-0.07 \mathrm{~g} / \mathrm{min}$. Ethanol was then delivered by the co-solvent pump at a flow rate of 0.6 or $1.3 \mathrm{~mL} / \mathrm{min}$ depending on the desired fluid composition of $15 \mathrm{wt} \%$ or $30 \mathrm{wt} \%$ in ethanol. According to the P-T-x bubble point curves [27], the pressure of $25 \mathrm{MPa}$ is far above the critical pressure of the $\mathrm{CO}_{2}: \mathrm{EtOH}$ mixture at $60{ }^{\circ} \mathrm{C}$, therefore the extracting $\mathrm{CO}_{2}: \mathrm{EtOH}$ mixture was monophasic whatever the ethanol percentage. The $\mathrm{CO}_{2}$ and cosolvent flow rates, delivered by two Gilson pumps (model 305, heads 25SC and 10SC, Gilson International, Villiers le Bel, France) were checked by a gasmeter and by the cosolvent volume consumption over time, respectively. A heater-cartridge (TOP Industrie SAS, Vaux le Pénil, France) heated the fluid mixture to the desired temperature of extraction prior to its introduction into the extractor vessel. At the extractor exit, the $\mathrm{CO}_{2}$ :ethanolic extract was vented to atmospheric pressure through a micrometering valve (Autoclave Engineer, Autoclave Maxitech, Rantigny, France) connected to a cyclonic separator whose flask at the bottom was immersed into ice. The extraction was carried out for $180 \mathrm{~min}$, then, pure supercritical $\mathrm{CO}_{2}$ was delivered for $90 \mathrm{~min}$ to flush out the ethanol and to 
recover the extract remaining in the pipes. Extracts were collected every $30 \mathrm{~min}$ or so by changing the trap flask, the last one being collected at the end of the $\mathrm{CO}_{2}$ flushing. The first extract when using $\mathrm{CO}_{2}$ :EtOH15\% was however collected at $60 \mathrm{~min}$. Extracts were stored at $18^{\circ} \mathrm{C}$ in amber vials until analysis. The $30 \% \mathrm{EtOH}$ experiment was duplicated for reproducibility assessment. The observed deviations were less than $5 \%$ for yields and less than $7 \%$ in extract compositions.

\subsubsection{Extraction by pressurized EtOH}

The use of pressurized ethanol as extraction solvent was assessed. Extractions were conducted in a dynamic mode since solvent continuously flowed through the matrix. They were carried out in the same apparatus as the $\mathrm{CO}_{2}$ : EtOH extractions. The system was first pressurized at 3 $\mathrm{MPa}$ with $\mathrm{CO}_{2}$ before introducing ethanol up to the desired pressure. Ethanol was then delivered at a flow rate of $1.5 \mathrm{~mL} / \mathrm{min}$. The pressure and the temperature were set at $6 \mathrm{MPa}$ and $60^{\circ} \mathrm{C}$ respectively. At the end of the 83 min dynamic extraction, neat $\mathrm{CO}_{2}$ was flowed to the extractor at $18 \mathrm{MPa}$ for $90 \mathrm{~min}$ to flush out ethanol and recover the extract remaining in the pipes. The extract was collected every 20 min by changing the trap flask, the last one being collected at the end of the $\mathrm{CO}_{2}$ flushing. The extracts were kept in amber vials at $-18^{\circ} \mathrm{C}$ until analysis. The experiment was duplicated for reproducibility assessment. Deviations were less than $7 \%$ in yields and extract compositions.

\subsection{Extract characterization}

Extracts were evaporated under reduced pressure (RE 300DB, Stuart ${ }^{\circledR}, \mathrm{UK}, 30 \mathrm{kPa}$ ) then freeze-dried (Cryotec lyophilizer, Cosmos - 80, France, vacuum $6.7 \mathrm{~Pa} ;-85{ }^{\circ} \mathrm{C}$ ). The global extraction yield is expressed as the amount of extract per $100 \mathrm{~g}$ of dry pomegranate residue. The dried extracts were dissolved in aqueous ethanol for analysis.

Total sugars and total phenolic compounds were quantified as summarized in [28]. Briefly, the amount of total sugars was evaluated using the anthrone-sulfuric acid assay in which carbohydrates were hydrolyzed $(150 \mu \mathrm{L}$ of reagent for $50 \mu \mathrm{L}$ of sample) and the resulting furfuralic compounds were assayed by measuring the absorbance at $620 \mathrm{~nm}$ in microplates (Model UH5300, Hitachi, Tokyo, Japan) using a glucose calibration curve from 0 to 100 $\mathrm{mg} . \mathrm{L}^{-1}$. Analyses were performed at least in triplicate and observed variations were below 9\%. The total phenolic amount was quantified using Folin-Ciocalteu reagent (100 $\mu \mathrm{L}$ for 20 $\mu \mathrm{L}$ of sample), measuring the absorbance at $750 \mathrm{~nm}$ in microplates and calculating the TPC content thanks to a gallic acid calibration curve from 0 to $100 \mathrm{mg}$. $\mathrm{L}^{-1}$. It was checked that the 
amount of sugar in analyzed diluted samples did not interfere with the TPC determination (calibration curves in the presence of sugar were similar to the original calibration curve). Analyses were performed at least in triplicate and the observed variations were below $4.5 \%$.

Quantification of ellagic acid (EA) and punicalagin (PU) was carried out by HPLC analysis adapted from Poyrazoglu et al. [29], using an Agilent Infinity 1200 system (Agilent Technologies, Les Ulis, France) equipped with a Spherisorb ODS2 C18 (250 x $4.6 \mathrm{~mm}, 5 \mu \mathrm{m}$ particle size) column. The mobile phase, $1 \mathrm{~mL} / \mathrm{min}$, consisted of a gradient of $5 \%$ formic acid (A) and methanol (B). The gradient elution program was: 0 min, $10 \% \mathrm{~B} ; 20 \mathrm{~min}, 30 \% \mathrm{~B} ; 35$ $\min , 50 \% \mathrm{~B}$; $40 \mathrm{~min}, 90 \% \mathrm{~B} ; 44 \mathrm{~min}, 10 \% \mathrm{~B} ; 60 \mathrm{~min}, 10 \% \mathrm{~B}$. EA and PU were identified by their retention times and UV spectra while their quantification was performed by the external standard method (EA and PU standard solutions in methanol). Punicalagin is found in two forms $(\alpha-$ and $\beta)$ in pomegranates. The HPLC analysis allowed the detection of the two forms but the quantification was assayed as punicalagin (total of the two forms) since standards of each form do not exist. The calibration curves ranged from 0.1 to $44 \mu \mathrm{g}$ for PU and from 0.1 to $60 \mu \mathrm{g}$ for $\mathrm{EA}$

Identification of phenolics was performed by LC-MS with a mass spectrometer model QTRAP® 5500 (Sciex, Villebon sur Yvette, France) coupled to a LC system (Shimatzu, Marne-la-Vallée, France). Method is detailed in supplementary data together with mass spectra of some of the identified phenolic compounds. Among the 48 phenolic compounds identified by Fischer et al [30], 32 were detected in several extracts produced here. Most of these phenolics were hydrolysable tannins such as ellagitannins, and glycosylated phenolics. 


\section{RESULTS AND DISCUSSION}

\subsection{Yields and kinetics data}

Table 1 reports the specific yields obtained for different compounds or class of compounds when using the various techniques.

Table 1. Extraction yields of total extract, total phenolics (TPC), ellagic acid, punicalagin and total sugar obtained by the various extraction methods. GAE: gallic acid equivalent, GE: glucose equivalent, feed: dry pomegranate residue

\begin{tabular}{|l|c|c|c|c|c|}
\hline & $\begin{array}{c}\text { Extract yield } \\
\left(\mathrm{mg} / \mathrm{g}_{\text {feed }}\right)\end{array}$ & $\begin{array}{c}\text { TPC } \\
\left(\mathrm{mg} \mathrm{GAE} / \mathrm{g}_{\text {feed }}\right)\end{array}$ & $\begin{array}{c}\text { Ellagic acid } \\
\left(\mathrm{mg} / \mathrm{g}_{\text {feed }}\right)\end{array}$ & $\begin{array}{c}\text { Punicalagins* } \\
\left(\mathrm{mg} / \mathrm{g}_{\text {feed }}\right)\end{array}$ & $\begin{array}{c}\text { Sugars } \\
(\mathrm{mg} \mathrm{GE} / \\
\mathrm{g}_{\text {feed }}\end{array}$ \\
\hline Ethanol maceration & 466 & $33+/-2$ & $1.1+/-0.1$ & $1.3+/-0.1$ & $214+/-13$ \\
\hline Water maceration & 603 & $67+/-1$ & $2.0+/-0.1$ & $9.4+/-0.1$ & $406+/-10$ \\
\hline $\begin{array}{l}\text { Ethanol:water 50:50 v\% } \\
\text { maceration }\end{array}$ & 608 & $71+/-3$ & $3.2+/-0.1$ & $14.7+/-0.1$ & $271+/-11$ \\
\hline $\mathrm{CO}_{2}$ : EtOH 85:15 w\% & 116 & $1.4+/-0.1$ & $0.65+/-0.1$ & - & $60+/-1$ \\
\hline $\mathrm{CO}_{2}:$ EtOH 70:30 w\% & $367+/-26$ & $3.5+/-0.2$ & $1.3+/-0.1$ & - & $198+/-7$ \\
\hline Pressurized ethanol & $520+/-10$ & $39+/-2$ & $2.9+/-0.2$ & $2.1+/-0.2$ & $368+/-17$ \\
\hline
\end{tabular}

Results are given as mean +/- standard deviation based on 2 replications for CO2:EtOH 70:30 w\% and pressurized ethanol, and, for each sample, on 3 HPLC analyses for EA and PU determinations and 3 to 5 analyses for TPC and sugar quantifications. *: quantification of punicalagin is given as the total of the two forms $\alpha$ and $\beta$ anomers

Extraction yield. The global extraction yields were above $466 \mathrm{mg} / \mathrm{g}_{\text {feed }}$ in all cases except for extractions using $\mathrm{scCO}_{2}$. Macerations in pure water or in combination with ethanol (50:50 vol\%) led to similar yields of $600 \mathrm{mg} / \mathrm{g}_{\text {feed }}$, a value that was consistent with the $614 \mathrm{mg} / \mathrm{g}_{\text {feed }}$ reported by Saffarzadeh et al [21] for similar residue and close conditions. High yields are not uncommon for pomegranate extractions though discrepancies may exist between studies. For instance, using water as extracting solvent from peels, Cam [22] and Wang [15] reported very different yields of $17 \%$ and $43 \%$, respectively, whereas they obtained the same yield of $46 \%$ when methanol was used.

Compared to macerations performed at atmospheric pressure, the use of a $\mathrm{CO}_{2}: \mathrm{EtOH}$ mixture led to smaller yields though a notable increase was shown when the ethanol content increased. The obtained range of yield was consistent with values of $85 \mathrm{mg} / \mathrm{g}_{\text {feed }}$ [20] and $189.1 \mathrm{mg} / \mathrm{g}_{\text {feed }}[16]$ reported in the case of extraction of pomegranate peels by $\mathrm{CO}_{2}: 10-20 \%$ 
EtOH. It is worth noting that when the extraction was performed using neat $\mathrm{CO}_{2}$ the extraction yield was almost zero. The addition of ethanol hence led to a significant increase of the extracted amount. The ability of this cosolvent to develop a molecular affinity for polar compounds is well known [31]. Regarding pressurized ethanol, the global yield was slightly improved compared to maceration.

In order to more accurately discuss the methods, the global extraction kinetics are given in Fig.1 as function of time (Fig. 1A) or as function of the solvent volume-to-mass ratio (or cosolvent volume in the case of $\mathrm{CO}_{2}$-based extractions) (Fig. 1B) to better address solubilization issues.

The three macerations with water, ethanol and water:EtOH mixture exhibited a similar extraction curve shape with 64 to $75 \%$ of the total amount recovered during the first extraction step. The extraction rate (slope of the curve) then slowed down especially at the third maceration indicating a progressive exhaustion of the pomegranate residue in extractable compounds. Compared to water or hydroalcoholic mixture, pure ethanol led to lower yields that showed a lower solubilization ability of that solvent.

Regarding the three pressurized extractions, the curve for $\mathrm{CO}_{2}: 30 \% \mathrm{EtOH}$ exhibited a typical profile with a first constant rate period attributed to a limitation by solubility followed by a period of slower rate indicative of a limitation by mass transfer [32]. The increase of the ethanol content from 15 to $100 \%$ strongly increased the initial rate indicating a marked enhancement of the solubility in the resulting solvent. At $15 \%$ of ethanol, the limitation by the poor solubility lasted the whole duration of the extraction. In the plot of yield as a function of the volume to solid ratio (Fig 1B), the ratio was calculated by considering only the co-solvent volume for $\mathrm{CO}_{2}$ experiments so that the Vs/S was in the same order of magnitude as for the other conditions. The curves obtained at 15\%,30\% and 100\% ethanol did not coincide, indicating that though the same volume of ethanol was used, the solvation ability of this solvent strongly decreased when it was mixed with the apolar $\mathrm{CO}_{2}$. The plots also showed that, in the case of pure ethanol extraction, the pressure of $6 \mathrm{MPa}$ did not exert an important effect neither on the kinetics shape nor on the extraction yields.

Sugars extraction. All produced extracts were sticky, indicating a noticeable extraction of sugars. Noteworthy is that since analysis is performed after acid hydrolysis of extracts, it provides no information about the nature (oligosaccharides or polysaccharides) of sugars. The sugar extraction yield was found to vary between 60 and $406 \mathrm{mg} / \mathrm{g}_{\text {feed }}$ (Table 1). The 
lowest value was obtained at $\mathrm{CO}_{2}: 15 \%$ ethanol, i.e. for the solvent of lowest polarity. The fact that $\mathrm{CO}_{2}$ :ethanol mixture can solubilize carbohydrates was already demonstrated by solubility measurements [26] or by their co-extraction along with phenolics from carob biomass [33] or strawberry receptacles [34]. In maceration, the extraction of sugars increased with the water content of the solvent, going from $214 \mathrm{mg} \mathrm{GE} / \mathrm{g}_{\text {feed }}$ in pure ethanol to $406 \mathrm{mg} / \mathrm{g}_{\text {feed }}$ in pure water. According to Sato et al [33], the extraction of sugars is correlated to the dielectric constant of the solvent which increases with the water content of hydroalcoholic mixtures, because of the many hydroxyl groups present in the carbohydrates molecules. When ethanol was pressurized, a significant enhancement of sugar extraction was observed with a yield that attained $368 \mathrm{mg} / \mathrm{g}_{\text {feed }}$. Though moderate $(6 \mathrm{MPa})$, the pressure hence exerted a positive effect. It was assumed that pressure induced a structural modification of the plant cells causing less resistance for mass transfer.

Total Phenolic Content (TPC). When $\mathrm{CO}_{2}$ : EtOH was used as solvent, the global extraction of phenolics was very low, even though this amount increased with the cosolvent content. The gain was similar to that reported in literature when pomegranate peels were extracted [20]. The mixing of $\mathrm{CO}_{2}$ with EtOH increases the solvent polarity and improves phenolics solubility through solute-cosolvent hydrogen bonds [35]. Nonetheless, that mixture was not polar enough to extract phenolics as efficiently as pure ethanol for which an increase of 10fold was obtained for the yield. As with sugar extraction, the recovery of phenolics was enhanced by operating under pressure, a behavior already noticed in literature [36]. Water was found to be a more efficient solvent than ethanol for phenolics extraction, and slightly higher yield was obtained when ethanol and water were mixed. Although the relative efficacy of pure ethanol and pure water might be controversial in published studies, the literature tends to agree that hydroalcoholic solvents yield better performances for pomegranate phenolics recovery than the pure solvents $[7,15,18,37]$. The beneficial effect is ascribed to the influence of a widened solubilizing ability towards glycosylated phenolics, to the matrix swelling that facilitates the solvent penetration and to the weakening of the phenolic-matrix bonds. Regarding the range of yield obtained here compared to literature, Saffarzadeh et al [21] reported a value of $110 \mathrm{mg} \mathrm{GAE} / \mathrm{g}_{\text {waste }}$ in similar conditions, a yield that attained $230 \mathrm{mg}$ $\mathrm{GAE} / \mathrm{g}_{\text {waste }}$ under optimized conditions [4,21] . 
TPC is a global quantification of the amount of phenolic extracted but it gives no indication of the complexity of the extracted phenolic pool contrary to the HPLC analysis. Fig. 2 shows typical chromatograms obtained for extracts recovered by the various methods.

The chromatographic profiles of extracts obtained by ethanol, pressurized or not, or water/ethanol extraction (Fig 2B to 2D) exhibited many peaks especially at retention times between 2 and $20 \mathrm{~min}$. Chromatograms were rather similar in complexity though some differences in the relative intensity of peaks could be seen at the vicinity of punicalagins (PU) retention. Similar relative intensities of peaks, especially regarding PU and EA, were noticeable in chromatograms presented by Sumere et al. [23] for various aqueous ethanol extracts, with decreasing PU/EA ratio as ethanol ratio in solvent increased. On contrary, the chromatographic profile of the extract obtained with $\mathrm{CO}_{2}$ : EtOH $15 \%$ was much simpler since only few peaks were detected between 2 and 15 min whereas the ellagic acid peak (EA) was clearly visible at $35 \mathrm{~min}$ (Fig 2A). The chromatographic analysis therefore evidenced a selectivity provided by the $\mathrm{scCO}_{2}$-based extraction.

Ellagic acid and punicalagin yields. Ellagic acid and punicalagin are the major bioactive compounds in pomegranate. The simultaneous quantification of the two components in pomegranate extracts is however rarely addressed [21,38]. Punicalagin is an ellagitannin found in two forms that were well separated by HPLC (Fig. 2). The respective proportions of punicalagin $\mathrm{A}$ and $\mathrm{B}$ were $40 \%$ and $60 \%$, a ratio that was consistent with literature data [22]. EA and PU were both quantified and their global extraction yields were expressed in $\mathrm{mg} / \mathrm{g}$ pomegranate residue (Table 1). The maximum extraction yields of the two compounds were very different: $3.2 \mathrm{mg} / \mathrm{g}_{\text {feed }}$ for EA and $14.7 \mathrm{mg} / \mathrm{g}_{\text {feed }}$ for PU. Data reported in Table 1 showed the high specificity of the $\mathrm{scCO}_{2}: \mathrm{EtOH}$ solvent since punicalagins were not extracted even at the condition of $30 \%$ EtOH. In contrast, the extraction of ellagic acid was sensitive to the ethanol content and increased with it. The ethanol maceration allowed to extract both ellagitannins and the pressurization to $6 \mathrm{MPa}$ enhanced both EA and PU extractions but to a larger extend for EA. Water was a more influential solvent for PU and the overall behavior might be related to PU higher solubility in aqueous solvents than in alcohol, whereas EA is more soluble in solvents less polar than water [39]. Nevertheless, as with TPC, water and ethanol did show a synergic effect when mixed since the highest extraction yields were 
obtained with the hydroethanolic solvent. The values obtained were consistent with literature data $[21,38]$.

The kinetics of total phenolics (TPC), sugars, ellagic acid and punicalagins extractions are reported in Fig. 3. For better visualization, EA and PU yields were multiplied by 10 to be on the same scale as TPC for all figures except for $\mathrm{CO}_{2}: 15 \%$ EtOH and $\mathrm{CO}_{2}: 30 \% \mathrm{EtOH}$ (Fig. 3A and $3 \mathrm{~B}$ respectively). For TPC, the three macerations with ethanol (Fig. 3D), ethanol:water (Fig. 3E) and water (Fig. 3F) exhibited a similar curve shape with an extraction that slowed down at the third extraction though matrix exhaustion was not completed. The rate with ethanol as solvent was however lower than with the other solvents. Unlike TPC, extractions of PU and EA were almost completed though some PU could have been gained by performing more steps of macerations. From a process standpoint, continuing the extraction while the extraction rate decreases is however not economically attractive due to the larger solvent consumption and the recovery of more and more diluted solutions. For sugars, regardless of the solvent, 68 to $71 \%$ of the total amount were extracted during the first maceration whereas the third one contributed for less than $6 \%$. For extractions with pressurized solvents, the kinetics at $\mathrm{CO}_{2}: 15 \%$ EtOH (Fig. 3A) shows limitation by solubility throughout all duration of the extraction for each class of compounds. This limitation was already noticed for the total extraction yield (Fig. 1). It is worth reminding that the time for the last fraction corresponds to the last $\mathrm{CO}_{2}$ :EtOH extraction augmented by the duration of the system rinsing by neat $\mathrm{CO}_{2}$, so the apparent final slowing down is due to the time scale. For $\mathrm{CO}_{2}: 30 \% \mathrm{EtOH}$, the extraction rate was constant during $68 \mathrm{~min}$ then extraction slowed down to reach a plateau at $150 \mathrm{~min}$ (Fig. 3B). It is worth noting that all classes of compounds were present in the first extract whatever the techniques indicating that there were all quite readily accessible.

\subsection{Extract composition.}

The yield reflects the process performances but the composition is of great importance for assessing the extract quality. The composition of the final extracts produced by the various methods is given in Fig. 4.

Among the quantified classes, carbohydrates were predominant in all extracts even in those obtained at conditions of lower solvent polarity ( $\mathrm{scCO}_{2}$-based extractions). On dry weight basis, extracts were composed of sugars at 40 to $70 \%$. Regarding the phenolic contents, the 
various techniques originated large differences: 9.5 to $117.0 \mathrm{mg} \mathrm{GAE} / \mathrm{g}_{\mathrm{d} . \mathrm{e}}$ for $\mathrm{TPC}$, from 2.3 to $6.0 \mathrm{mg} / \mathrm{g}_{\mathrm{d} . \mathrm{e}}$ for EA and from 0 to $24.2 \mathrm{mg} / \mathrm{g}_{\mathrm{d} . \mathrm{e}}$ for PU. These values are consistent with those obtained by ultrasound extraction of peels [40]. The specificity of the $\mathrm{scCO}_{2}: \mathrm{EtOH}$ mixture was clearly evidenced since the obtained extracts were devoid of the water-soluble punicalagin but had concentrations of EA similar to the other extracts while containing the lowest amounts of phenolics and moderate concentration of sugar. Therefore, the selectivity between ellagic acid and punicalagin and, on the other hand, the purity of ellagic acid with respect to other phenolics was maximal. Extracts from pure ethanol showed similar concentrations of EA and PU. The pressurization increased notably the concentration in sugar, and this could contribute to the quite high content in sugar found in $\mathrm{scCO}_{2}$-based extracts. Macerations carried out with water-based solvents produced extracts with similar composition in total phenolics, but pure water clearly increased the content in sugars. On the other hand, water-based solvents exhibited a clear selectivity towards PU, since PU concentration of extracts was five times higher than that of EA. Therefore the EtOH:water mixture (50:50 v:v) appeared to be the best option to combine high levels in phenolics (117 mg GAE/ $\mathrm{g}_{\text {d.e }}$ ), EA (5 $\left.\mathrm{mg} / \mathrm{g}_{\text {d.e }}\right)$ and PU $\left(24 \mathrm{mg} / \mathrm{g}_{\text {d.e }}\right)$ to one of the lowest levels in sugars (445 mg GE/ $\left.\mathrm{g}_{\text {d.e }}\right)$.

The proposed methods were thus producing extracts of various composition opening opportunity to select the extraction method on purpose. Although not appropriate to achieve high extraction yields, $\mathrm{scCO}_{2}$ modified with ethanol was of particular interest since it provided the highest purity in ellagic acid. However, EA was always mixed with significant amounts of sugars in all extracts irrespective of the method. To our best knowledge, this is the first reported extraction method that leads in one step to an extract devoid of punicalagin and poor in other phenolics but rich in EA, i.e. at levels comparable to those obtained by any of the other methods. In literature, a two-step extraction procedure comprising an ethanol extraction followed by a partition of the extract in solvents of various polarity was developed to enrich extracts in ellagic acid and/or punicalagin $[9,38]$. However, none of these extracts contained only one of these two compounds. In addition, the selectivity obtained in this work might be further exploited to design a sequential extraction process enabling the recovery of two distinct fractions, one enriched in ellagic acid and the other in punicalagin. A first extraction by pressurized $\mathrm{scCO}_{2}: \mathrm{EtOH}$ would produce an ellagic acid extract and let a solid residue that could be further macerated in water or in water:ethanol mixture to recover punicalagin. Extraction combinations could also be guided by the recovery of sugar when aiming at producing extracts of limited sugar content. 


\section{CONCLUSION}

In this work, extractions were performed on a pomegranate residue made of peels and aril pomace to represent an industrial juice processing waste. Several extraction techniques employing different GRAS solvents and under different pressure conditions were implemented. For the first time, a systematic analysis of sugar extraction yields and measurement of sugar contents in extracts was performed. All extractions gave large extraction yields, up to $61 \%$, due to the high extraction of sugars even with the lower polarity solvents made by $\mathrm{CO}_{2}$ and $15-30 \%$ ethanol, because of the high pressure applied. The concentrations of sugars therefore ranged between 420 and $704 \mathrm{mg} \mathrm{GE} / \mathrm{g}$ of dry extract. Ellagic acid and punicalagin are the well-known bioactive phenolics in pomegranate. Since they display different biological activities, their individual extraction yields and contents in extracts were quantified in addition to the total phenolic content. The solvent was found to influence the extraction efficiency of these compounds inducing therefore a selectivity in the extract composition. The ethanol:water mixture allowed for obtaining the highest yield in phenolics including in EA and PU with five times higher concentration in PU compared to EA, and moderate concentration in sugar. The highest specificity was shown by the supercritical technology using $\mathrm{CO}_{2}: \mathrm{EtOH}$ mixture with 15 or $30 \mathrm{wt} \%$ in cosolvent since extracts did not contain PU but had similar concentrations of EA as the other extracts and contained the lowest amounts of phenolics. The technique therefore provided the highest purity in EA (accounting for $50 \%$ of the total phenolics) but at the detriment of yield compared to the ethanol:water maceration. The extraction efficiency was improved by an increasing cosolvent content of the $\mathrm{CO}_{2}: \mathrm{EtOH}$ mixtures mostly due to a positive effect on solubility since the kinetics of extraction at $15 \% \mathrm{EtOH}$ was shown to be limited by this parameter. Investigation of supercritical extraction using $\mathrm{CO}_{2}: \mathrm{EtOH}$ mixture would allow optimization of the EA extraction yield and may improve selectivity towards sugar content. For extractions performed by maceration with three steps, all compounds were significantly extracted by the first step with a minimum of $64 \%$ of the global extracted yield, but the kinetics study pointed the need for performing additional extractions if higher yields were desired. 


\section{Acknowledgements}

The authors gratefully acknowledge Gabes University, Tunisia, for the B. Khoualdia's 2months scholarship at CBMN in France.

\section{Conflict of Interest Statement}

The authors declare no conflict of interest.

This research did not receive any specific grant from funding agencies in the public, commercial, or not-for-profit sectors.

\section{References}

[1] T. Ismail, P. Sestili, S. Akhtar, Pomegranate peel and fruit extracts: A review of potential anti-inflammatory and anti-infective effects, Journal of Ethnopharmacology. 143 (2012) 397-405. https://doi.org/10.1016/j.jep.2012.07.004.

[2] Z. Kalaycıoğlu, F.B. Erim, Total phenolic contents, antioxidant activities, and bioactive ingredients of juices from pomegranate cultivars worldwide, Food Chemistry. 221 (2017) 496-507. https://doi.org/10.1016/j.foodchem.2016.10.084.

[3] B. Gultekin Subasi, H. Alpas, Effect of high hydrostatic pressure processing and squeezing pressure on some quality properties of pomegranate juice against thermal treatment, High Pressure Research. (2016) 1-15. https://doi.org/10.1080/08957959.2016.1263840.

[4] E. Amyrgialaki, D.P. Makris, A. Mauromoustakos, P. Kefalas, Optimisation of the extraction of pomegranate (Punica granatum) husk phenolics using water/ethanol solvent systems and response surface methodology, Industrial Crops and Products. 59 (2014) 216-222. https://doi.org/10.1016/j.indcrop.2014.05.011.

[5] S. Talekar, A.F. Patti, R. Singh, R. Vijayraghavan, A. Arora, From waste to wealth: High recovery of nutraceuticals from pomegranate seed waste using a green extraction process, Industrial Crops and Products. 112 (2018) 790-802. https://doi.org/10.1016/j.indcrop.2017.12.023.

[6] F. Turrini, R. Boggia, D. Donno, B. Parodi, G. Beccaro, S. Baldassari, M.G. Signorello, S. Catena, S. Alfei, P. Zunin, From pomegranate marcs to a potential bioactive ingredient: a recycling proposal for pomegranate-squeezed marcs | SpringerLink, European Food Research and Technology. 246 (2020) 273-285.

[7] B. Singh, J.P. Singh, A. Kaur, N. Singh, Phenolic compounds as beneficial phytochemicals in pomegranate ( Punica granatum L.) peel: A review, Food Chemistry. 261 (2018) 75-86. https://doi.org/10.1016/j.foodchem.2018.04.039.

[8] S. Akhtar, T. Ismail, D. Fraternale, P. Sestili, Pomegranate peel and peel extracts: Chemistry and food features, Food Chemistry. 174 (2015) 417-425. https://doi.org/10.1016/j.foodchem.2014.11.035.

[9] K. Šavikin, J. Živković, A. Alimpić, G. Zdunić, T. Janković, S. Duletić-Laušević, N. Menković, Activity guided fractionation of pomegranate extract and its antioxidant, antidiabetic and antineurodegenerative properties, Industrial Crops and Products. 113 (2018) 142-149. https://doi.org/10.1016/j.indcrop.2018.01.031. 
[10] M.E. Clementi, G. Pani, B. Sampaolese, G. Tringali, Punicalagin reduces H2O2-induced cytotoxicity and apoptosis in PC12 cells by modulating the levels of reactive oxygen species, Nutritional Neuroscience. 21 (2018) 447-454. https://doi.org/10.1080/1028415X.2017.1306935.

[11] J. Tang, B. Li, S. Hong, C. Liu, J. Min, M. Hu, Y. Li, Y. Liu, L. Hong, Punicalagin suppresses the proliferation and invasion of cervical cancer cells through inhibition of the $\beta$-catenin pathway, Molecular Medicine Reports. 16 (2017) 1439-1444. https://doi.org/10.3892/mmr.2017.6687.

[12] B. Kang, C.Y. Kim, J. Hwang, K. Jo, S. Kim, H.J. Suh, H.-S. Choi, Punicalagin, a Pomegranate-Derived Ellagitannin, Suppresses Obesity and Obesity-Induced Inflammatory Responses Via the Nrf2/Keap1 Signaling Pathway, Molecular Nutrition \& Food Research. 63 (2019) 1900574. https://doi.org/10.1002/mnfr.201900574.

[13] Y. Goyal, A. Koul, P. Ranawat, Ellagic acid ameliorates cisplatin induced hepatotoxicity in colon carcinogenesis, Environmental Toxicology. 34 (2019) 804-813. https://doi.org/10.1002/tox.22747.

[14] J.-L. Ríos, R.M. Giner, M. Marín, M.C. Recio, A Pharmacological Update of Ellagic Acid, Planta Med. 84 (2018) 1068-1093. https://doi.org/10.1055/a-0633-9492.

[15] Z. Wang, Z. Pan, H. Ma, G.G. Atungulu, Extract of phenolics from pomegranate peels, The Open Food Science Journal. 5 (2011) 17-25.

[16] M. Mushtaq, B. Sultana, F. Anwar, A. Adnan, S.S.H. Rizvi, Enzyme-assisted supercritical fluid extraction of phenolic antioxidants from pomegranate peel, The Journal of Supercritical Fluids. 104 (2015) 122-131.

https://doi.org/10.1016/j.supflu.2015.05.020.

[17] P.D. Pathak, S.A. Mandavgane, B.D. Kulkarni, Valorization of Pomegranate Peels: A Biorefinery Approach, Waste and Biomass Valorization. 8 (2017) 1127-1137. https://doi.org/10.1007/s12649-016-9668-0.

[18] R. Tabaraki, E. Heidarizadi, A. Benvidi, Optimization of ultrasonic-assisted extraction of pomegranate (Punica granatum L.) peel antioxidants by response surface methodology, Separation and Purification Technology. 98 (2012) 16-23. https://doi.org/10.1016/j.seppur.2012.06.038.

[19] F. Turrini, P. Zunin, S. Catena, C. Villa, S. Alfei, R. Boggia, Traditional or hydrodiffusion and gravity microwave coupled with ultrasound as green technologies for the valorization of pomegranate external peels, Food and Bioproducts Processing. 117 (2019) 30-37. https://doi.org/10.1016/j.fbp.2019.06.014.

[20] A. Bustamante, A. Hinojosa, P. Robert, V. Escalona, Extraction and microencapsulation of bioactive compounds from pomegranate (Punica granatum var. Wonderful) residues, Int J Food Sci Technol. 52 (2017) 1452-1462. https://doi.org/10.1111/ijfs. 13422.

[21] S. Saffarzadeh-Matin, F.M. Khosrowshahi, Phenolic compounds extraction from Iranian pomegranate (Punica granatum) industrial waste applicable to pilot plant scale, Industrial Crops and Products. 108 (2017) 583-597. https://doi.org/10.1016/j.indcrop.2017.07.022.

[22] M. Çam, Y. Hış1l, Pressurised water extraction of polyphenols from pomegranate peels, Food Chemistry. 123 (2010) 878-885. https://doi.org/10.1016/j.foodchem.2010.05.011.

[23] B.R. Sumere, M.C. de Souza, M.P. dos Santos, R.M.N. Bezerra, D.T. da Cunha, J. Martinez, M.A. Rostagno, Combining pressurized liquids with ultrasound to improve the extraction of phenolic compounds from pomegranate peel (Punica granatum L.), Ultrasonics Sonochemistry. 48 (2018) 151-162. https://doi.org/10.1016/j.ultsonch.2018.05.028.

[24] T.P. Magangana, N.P. Makunga, O.A. Fawole, U.L. Opara, Processing Factors Affecting the Phytochemical and Nutritional Properties of Pomegranate (Punica granatum L.) Peel 
Waste: A Review, Molecules. 25 (2020) 4690.

https://doi.org/10.3390/molecules25204690.

[25] T. Bardeau, R. Savoire, M. Cansell, P. Subra-Paternault, Recovery of oils from press cakes by CO2-based technology, OCL. 22 (n.d.) D403.

https://doi.org/10.1051/ocl/2015004.

[26] R. Savoire, P. Subra-Paternault, T. Bardeau, E. Morvan, A. Grélard, M. Cansell, Selective extraction of phospholipids from food by-products by supercritical carbon dioxide and ethanol and formulating ability of extracts, Separation and Purification Technology. 238 (2020) 116394. https://doi.org/10.1016/j.seppur.2019.116394.

[27] C. Secuianu, V. Feroiu, D. Geană, Phase behavior for carbon dioxide+ethanol system: Experimental measurements and modeling with a cubic equation of state, The Journal of Supercritical Fluids. 47 (2008) 109-116. https://doi.org/10.1016/j.supflu.2008.08.004.

[28] C. Joseph, R. Savoire, C. Harscoat-Schiavo, D. Pintori, J. Monteil, F. Leal-Calderon, C. Faure, O/W Pickering emulsions stabilized by cocoa powder: Role of the emulsification process and of composition parameters, Food Research International. 116 (2019) 755766. https://doi.org/10.1016/j.foodres.2018.09.009.

[29] E. Poyrazoğlu, V. Gökmen, N. Artık, Organic Acids and Phenolic Compounds in Pomegranates (Punica granatum L.) Grown in Turkey, Journal of Food Composition and Analysis. 15 (2002) 567-575. https://doi.org/10.1006/jfca.2002.1071.

[30] U.A. Fischer, R. Carle, D.R. Kammerer, Identification and quantification of phenolic compounds from pomegranate (Punica granatum L.) peel, mesocarp, aril and differently produced juices by HPLC-DAD-ESI/MSn, Food Chemistry. 127 (2011) 807-821. https://doi.org/10.1016/j.foodchem.2010.12.156.

[31] M. Hamburger, D. Baumann, S. Adler, Supercritical carbon dioxide extraction of selected medicinal plants - effects of high pressure and added ethanol on yield of extracted substances, Phytochemical Analysis. 15 (2004) 46-54. https://doi.org/10.1002/pca.743.

[32] G.J. Tita, A. Navarrete, Á. Martín, M.J. Cocero, Model assisted supercritical fluid extraction and fractionation of added-value products from tobacco scrap, The Journal of Supercritical Fluids. (2020) 105046. https://doi.org/10.1016/j.supflu.2020.105046.

[33] L.B. Roseiro, L.C. Duarte, D.L. Oliveira, R. Roque, M.G. Bernardo-Gil, A.I. Martins, C. Sepúlveda, J. Almeida, M. Meireles, F.M. Gírio, A.P. Rauter, Supercritical, ultrasound and conventional extracts from carob (Ceratonia siliqua L.) biomass: Effect on the phenolic profile and antiproliferative activity, Industrial Crops and Products. 47 (2013) 132-138. https://doi.org/10.1016/j.indcrop.2013.02.026.

[34] T. Sato, F. Fukuda, K. Nihei, N. Itoh, Effect of temperature and pressure on the extraction of strawberry receptacles with a mixture of supercritical carbon dioxide and entrainers, The Journal of Supercritical Fluids. 130 (2017) 23-29. https://doi.org/10.1016/j.supflu.2017.07.011.

[35] D.L. Gurina, E.G. Odintsova, V.A. Golubev, M.L. Antipova, V.E. Petrenko, Features of solvation of phenolic acids in supercritical carbon dioxide modified by methanol and acetone, The Journal of Supercritical Fluids. 124 (2017) 50-56. https://doi.org/10.1016/j.supflu.2017.01.012.

[36] E.M.C. Alexandre, P. Araújo, M.F. Duarte, V. de Freitas, M. Pintado, J.A. Saraiva, Experimental Design, Modeling, and Optimization of High-Pressure-Assisted Extraction of Bioactive Compounds from Pomegranate Peel, Food Bioprocess Technol. 10 (2017) 886-900. https://doi.org/10.1007/s11947-017-1867-6.

[37] A. Zuorro, G. Maffei, R. Lavecchia, Effect of solvent type and extraction conditions on the recovery of phenolic compounds from artichoke waste, Chemical Engineering Transactions. 39 (2014) 463-468. https://doi.org/10.3303/CET1439078. 
[38] A. Masci, A. Coccia, E. Lendaro, L. Mosca, P. Paolicelli, S. Cesa, Evaluation of different extraction methods from pomegranate whole fruit or peels and the antioxidant and antiproliferative activity of the polyphenolic fraction, Food Chemistry. 202 (2016) 59-69. https://doi.org/10.1016/j.foodchem.2016.01.106.

[39] S. Alfei, F. Turrini, S. Catena, P. Zunin, M. Grilli, A.M. Pittaluga, R. Boggia, Ellagic acid a multi-target bioactive compound for drug discovery in CNS? A narrative review, European Journal of Medicinal Chemistry. 183 (2019) 111724. https://doi.org/10.1016/j.ejmech.2019.111724.

[40] J. Živković, K. Šavikin, T. Janković, N. Ćujić, N. Menković, Optimization of ultrasound-assisted extraction of polyphenolic compounds from pomegranate peel using response surface methodology, Separation and Purification Technology. 194 (2018) 4047. https://doi.org/10.1016/j.seppur.2017.11.032.
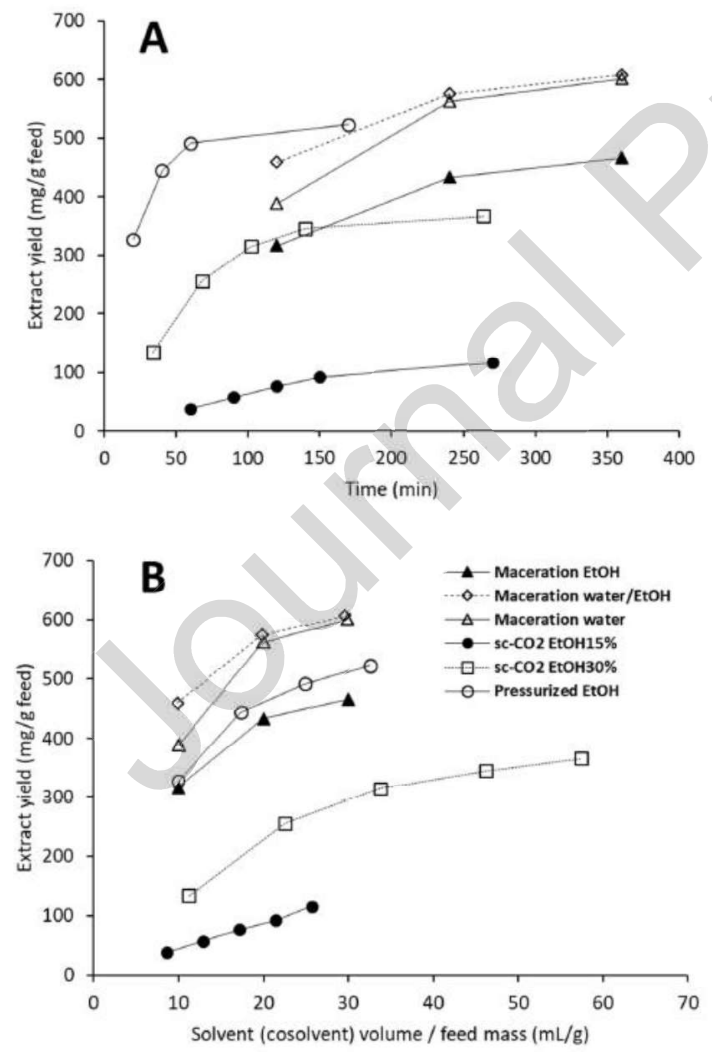

Fig. 1. Kinetics of extraction in terms of extract yield as a function of (A) time or as function of (B) the volume of solvent (cosolvent in case of $\mathrm{CO}_{2}$-based extraction) used per $\mathrm{g}$ of pomegranate feed ( $\mathrm{Vs} / \mathrm{S}$ ratio), for the various implemented methods. Lines are only guides for eyes. Extraction conditions: $60^{\circ} \mathrm{C}$; sc- $\mathrm{CO}_{2}$ extractions performed at $25 \mathrm{MPa}$ by $\mathrm{CO}_{2}: \mathrm{EtOH}$ mixtures (fluid composition of $15 \mathrm{wt} \%$ or $30 \mathrm{wt} \%$ ethanol); dynamic pressurized ethanol extraction performed at $6 \mathrm{MPa}$. 

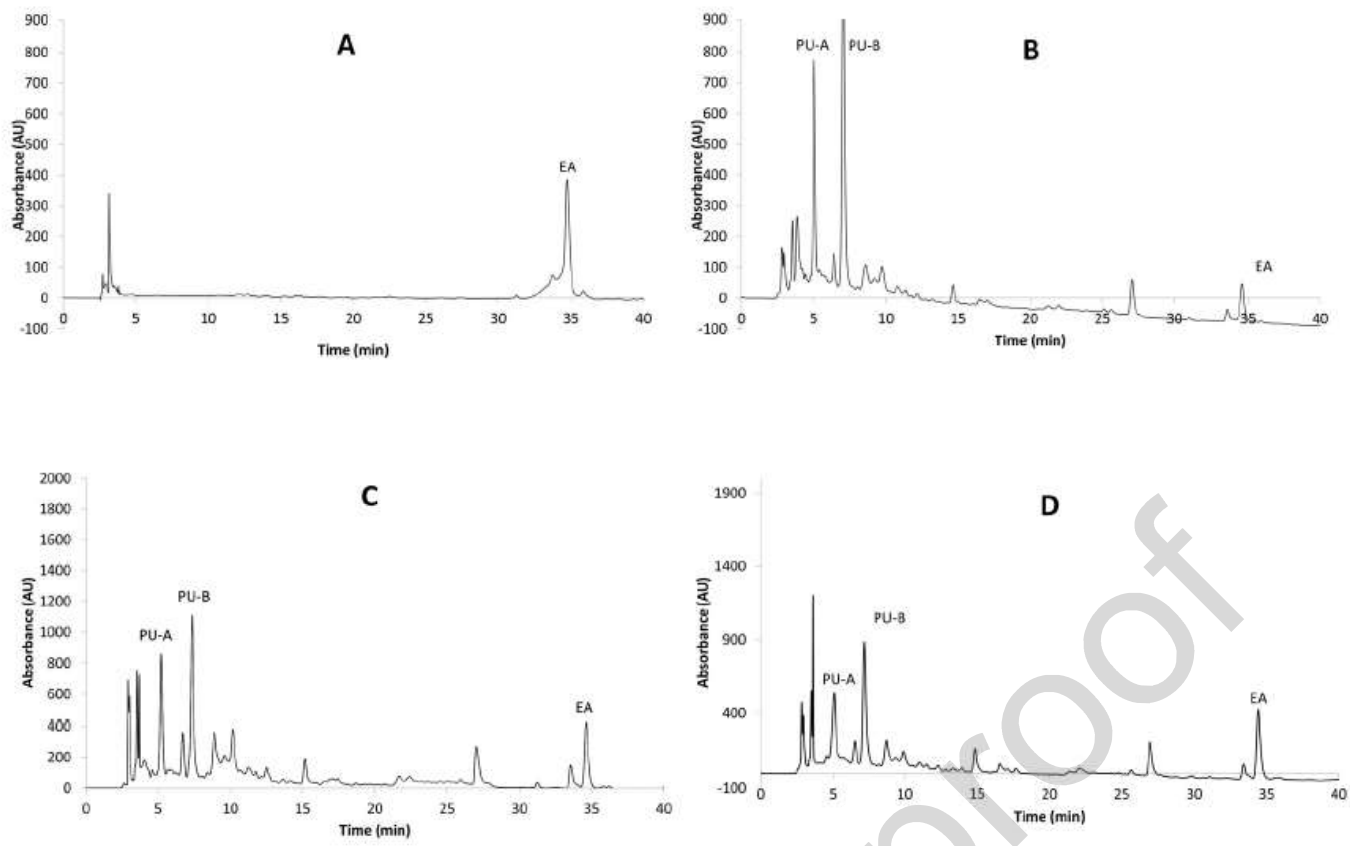

Fig. 2. HPLC chromatograms at $\lambda=280 \mathrm{~nm}$ of extracts obtained by (A) $\mathrm{CO}_{2}: 15 \%$ $\mathrm{EtOH}$; (B) ethanol:water maceration; (C) pressurized ethanol; (D) ethanol maceration. PU-A, punicalagin $\alpha$-anomer; PU-B, punicalagin $\beta$-anomer; EA, ellagic acid. 

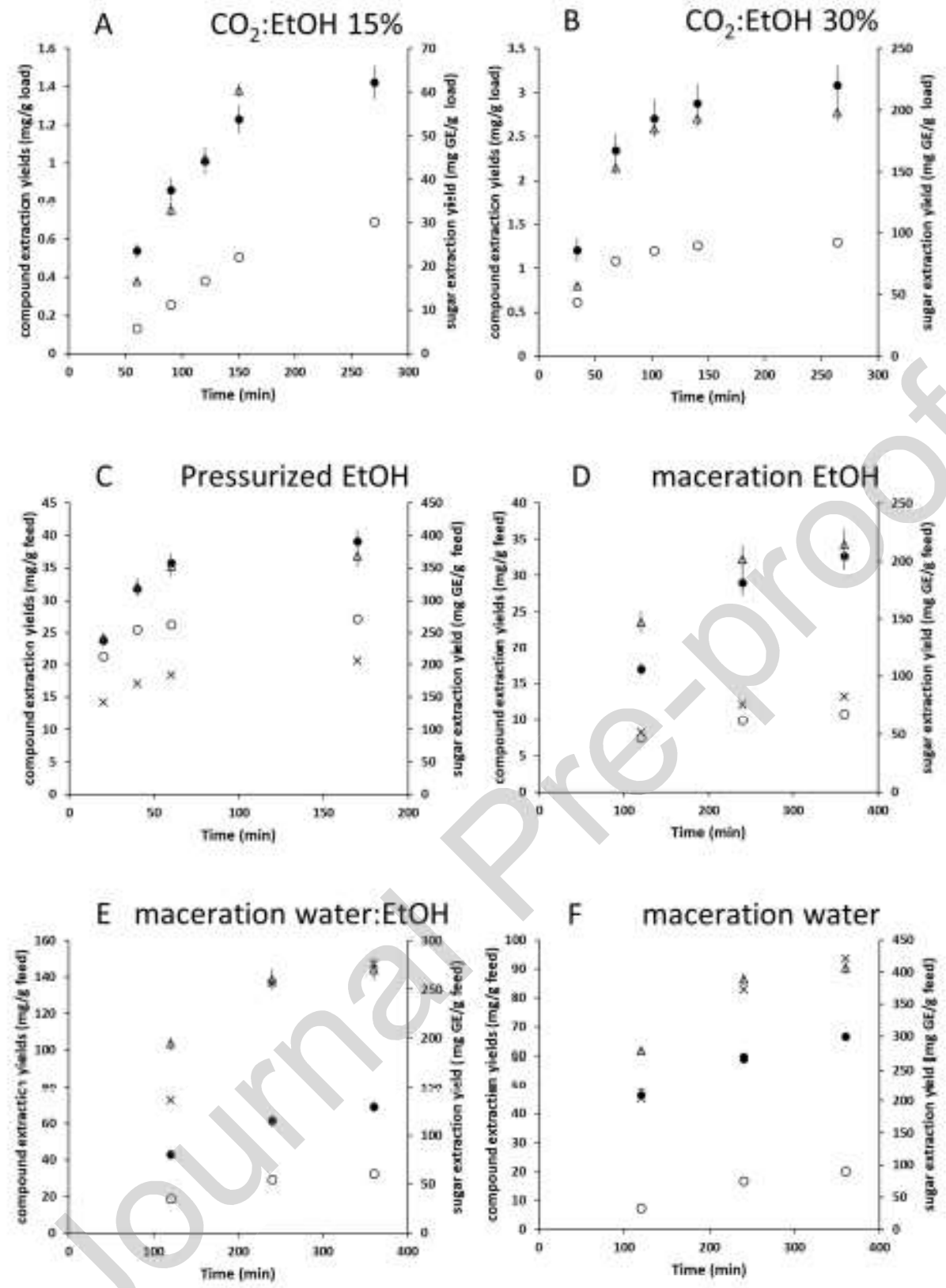

Fig. 3. Kinetics of extraction of total phenolics (TPC), sugars, ellagic acid (EA) and punicalagins (PU) for the various methods. A and B: o ellagic acid (mg EA/g $\left./ \mathrm{g}_{\text {feed }}\right), x$ punicalagin ( $\mathrm{mg}$ PU/ $\left.\mathrm{g}_{\text {feed }}\right), \bullet$ TPC (mg $\left.\mathrm{GAE} / \mathrm{g}_{\text {feed }}\right), \Delta$ sugar (mg GE/ $\left.\mathrm{g}_{\text {feed }}\right)$. C to F: o ellagic acid (x $10 \mathrm{mg} \mathrm{EA} / \mathrm{g}_{\text {feed }}$ ), x punicalagin ( $10 \mathrm{mg} \mathrm{PU} /$ $\left.\mathrm{g}_{\text {feed }}\right), \bullet$ TPC (mg GAE/ $\left.\mathrm{g}_{\text {feed }}\right), \Delta$ sugar (mg GE/ gfeed). 

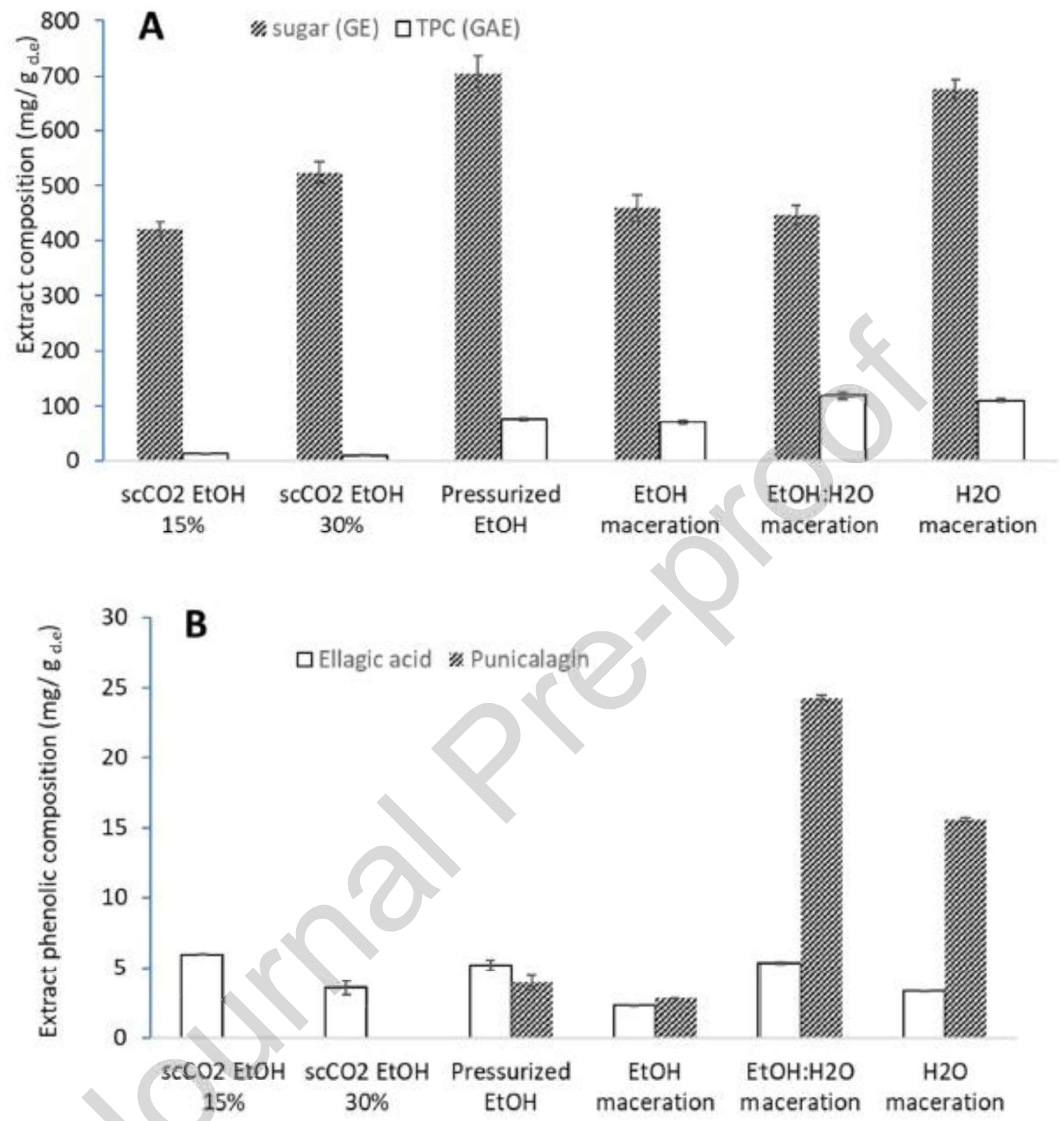

Fig. 4. Composition (in $\mathrm{mg} / \mathrm{g}$ dry extract) of extracts produced by the various extraction methods in A: total phenolics (TPC, mg GAE/ $\mathrm{g}_{\mathrm{d} . \mathrm{e}}$ ) and sugars (mg GE/ $\mathrm{g}_{\mathrm{d} . \mathrm{e}}$ ); B: ellagic acid ( $\left.\mathrm{mg} \mathrm{EA} / \mathrm{g}_{\mathrm{d} . \mathrm{e}}\right)$ and punicalagin $\left(\mathrm{mg} \mathrm{PU} / \mathrm{g}_{\mathrm{d} . \mathrm{e}}\right)$. d.e.: dry extract. 